\title{
Molecular Profiling and Research of Therapeutic Targets
}

\author{
Sumera Rizvi Gregory J. Gores \\ Division of Gastroenterology and Hepatology, Mayo Clinic College of Medicine, Rochester, Minn., USA
}

\begin{abstract}
Key Words
Hepatocellular carcinoma $\cdot$ Immune modulation · Synthetic lethality
\end{abstract}

\begin{abstract}
The heterogeneous nature of hepatocellular carcinoma (HCC) poses a challenge to effective therapy. Significant strides have been made in molecular profiling. Telomerase promoter mutations are now known to represent early events in linear carcinogenesis. However, the translation of these advances into clinical practice has been limited. Although further work is needed to extrapolate genetic information to patient care, progress has been made in using genetics and stratification for HCC therapy. Targeted therapies for patients with c-MET overexpression, VEGF-A amplification and Wnt $\beta$-catenin-driven tumors offer promise.
\end{abstract}

(c) 2015 S. Karger AG, Basel

\section{Introduction}

When assessing molecular profiling and its ramifications for therapy, one always feels like they are looking through a half-open door into the future without being able to see what is truly behind the door. Molecular profiling has undergone a tremendous evolution in the last decade. This has involved technological changes from focusing on genome-wide association studies to next-gen- eration sequencing, analysis of noncoding RNAs, epigenetic changes, copy number variations and examination for fusion genes. A tremendous amount of information has been gleaned from these efforts, but very few have impacted on clinical care. In a frustrating fashion, we have learned that hepatocellular cancer is incredibly heterogeneous. It is heterogeneous in regards to etiology amongst different patients, genetically between nodules in the same patient, and even within nodules of the same patient. Furthermore, there are local tissue effects such as hypoxia, posttreatment response, etc., which affect gene expression within tumors. Driver oncogenes have yet to be established for hepatocellular carcinoma (HCC). The total complexity of cancer progression can be conceptualized using trees as a visual image. For example, it is possible that a cancer clone may remain relatively stable for a protracted period of time only to undergo evolutionary changes late in its disease progression, as one might envisage would occur with a palm tree [1]. Such tumors would be predicted to be relatively easy to treat with a targeted therapy for long periods of time. In contrast, some trees branch out rapidly with multiple clones forming almost simultaneously. These cancers can be very difficult to treat given the multiclonality of the progression process. Indeed, using this analogy, HCC appears to function much more like a bush. Furthermore, we are only in our infancy in terms of being able to extrapolate the genetic information to patient care. Herein, we highlight recent advances and future directions of the field.

\section{KARGER 125}

C 2015 S. Karger AG, Base

$0257-2753 / 15 / 0334-0586 \$ 39.50 / 0$ 


\section{Genetic Profiling}

In assessing genetic aberrations in cancer one has to distinguish between driver mutations and passenger mutations. Driver mutations are thought to be instrumental in cancer initiation and progression while passenger mutations reflect bystander alterations to the genome which are not integral to the genesis or progression of the cancer. However, we note that this is an arbitrary distinction and it is possible that under certain conditions driver genes become passenger genes and vice versa. We now know that HCC is quite heterogeneous in its potential driver mutations [2]. There is a low frequency of inflammatory gene mutations regulating the interleukin- 6 and JAK/STAT pathways. Gene alterations modulating oxidative stress have recently been identified and reported. There is a low level of gene alterations in FGF19 and PIK3CA, which affect the MAPK and AKT/mTOR pathways, respectively. Additional alterations occur in genes modifying chromatin and cell cycle regulation. One of the more common genetic alterations in HCCs drives the $\beta$-catenin signaling pathway. More recently, it was demonstrated that telomerase maintenance pathways are altered in HCC. Not only are they altered in established HCC, but also seem to be integral to the development of this cancer [3]. For example, telomerase promoter mutations have been identified in early HCC from patients with hepatitis $B$, hepatitis $C$, and alcoholic and nonalcoholic steatohepatitis. They are present in dysplastic nodules and early HCC. Interestingly, they have also been identified in oral contraceptive-related hepatic adenomas which degenerate into HCC. Thus, in two different models of liver carcinogenesis, telomerase mutations were identified in a large fraction of these early premalignant and malignant lesions. This information may become important as we stratify patients for chemoprevention or develop telomerase-based therapies.

Recently, a 5-gene liver cancer-related signature was identified which predicted recurrence of cancer in patients following liver resection [4]. The 5 genes were HN1, RAN, RAMP3, KRT19 and TAF9. You will note that none of these are known driver mutations. They are also functionally unrelated genes. Nonetheless, their combined expression pattern, especially when combined with the BCLC staging system, is useful in predicting cancer prognosis. The 5-gene signature was associated with HCC recurrence following hepatic resection in regards to recurrence-free survival, overall survival and disease-specific survival. Thus, this turned out to be a very predictive 5 -gene signature. Its exact clinical utility remains uncer- tain. It is unclear whether it could be used to determine which patients to operate on, exclude from liver transplantation, or refer for other potential curative therapies. These issues are pertinent clinical questions which require validation in prospective studies.

\section{Therapeutic Targets}

A tremendous emphasis has been placed on the inhibition of receptor tyrosine kinases for solid tumors. Indeed, much of the success of targeted therapies has been in the realm of inhibiting receptor tyrosine kinases. One such receptor tyrosine kinase overexpressed in HCC is the hepatocyte growth factor receptor, c-MET $[5,6]$. Hepatocyte growth factor binds to c-MET resulting in its dimerization, which then via phosphorylation cascades results in activation of the Ras/Raf/MAPK pathway, the AKT/ mTOR pathway and the PKC pathway. Using a very sophisticated approach, the c-MET inhibitor tivantinib was therapeutically employed in a phase II trial for HCC. Patients were stratified using immunohistochemistry for c-MET expression. They were divided into patients with low and high expression levels. There was minimal difference in overall survival between placebo and tivantinib in the whole population. However, when patients were stratified according to c-MET expression, there was a significant benefit for patients with c-MET overexpression who received tivantinib therapy [6]. This was the first illustration of combining a biomarker with targeted therapy for the treatment of HCC. Phase III trials are in process for tivantinib. Indeed, there are a wide variety of c-MET inhibitors available and cabozantinib is also in a phase III trial for the treatment of HCC.

Sorafenib has become the first-line therapy for patients with advanced HCC [7]. Sorafenib inhibits receptor tyrosine kinases but was developed as a BRAF inhibitor. Thus, sorafenib is a multikinase inhibitor. It also inhibits members of the vascular endothelial growth factor (VEGF) receptor family. Sorafenib in nonstratified patients with advanced HCC is effective in improving time to progression and overall survival, as was demonstrated in the SHARP trial in 2008 [7]. Biomarkers identifying patients more likely to respond to sorafenib were not identified in that study. However, more recently, a paper was published in Cancer Discovery demonstrating that some patients with HCC have overamplification of the gene for VEGF-A [8]. Such patients were observed to respond quite dramatically to sorafenib in a retrospective analysis. The biology is complicated but suggests that 
Fig. 1. Synthetic lethality occurs when the presence of a certain genetic aberration in a cancer renders a particular gene (e.g. Gene A) essential and hence sensitizes to cell death via selective targeting of this gene. A wild-type genotype in a normal cell lacks the sensitizing genetic aberration rendering Gene A nonessential. Inhibiting Gene A in this setting does not result in cell death.

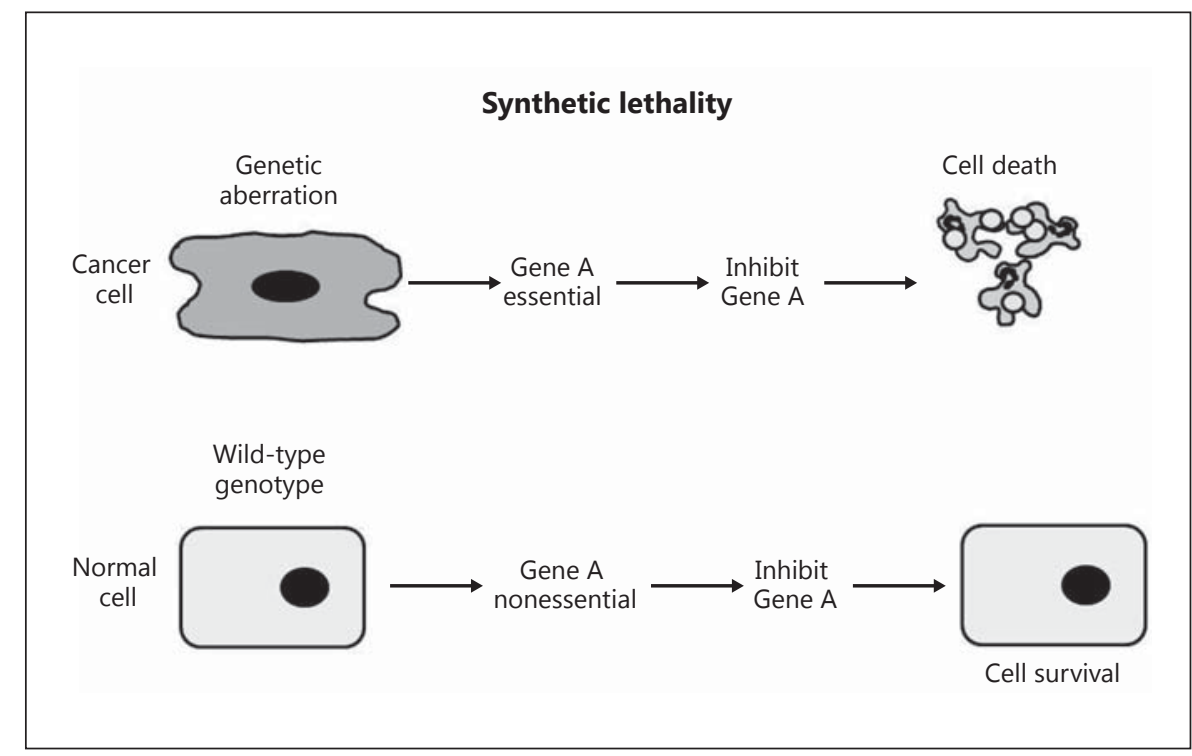

VEGF-A is secreted by HCCs. This results in activated endothelial cells and promotes the recruitment of protumorigenic macrophages to the HCC microenvironment. The activated endothelial cells and protumorigenic macrophages secrete factors such as hepatocyte growth factor which then, in a feed-forward loop, promote tumor progression. On the other hand, in the presence of sorafenib, the VEGF-A secretion effects are reduced leading to a decrease in mitogens and vascularity of the tumor, providing an antitumor effect.

It has been widely appreciated that a subset of HCCs are characterized by Wnt activation and enhanced $\beta$-catenin signaling as published by several groups employing expression profiling of HCCs $[9,10]$. In addition, it has been known for years that glypican-3 is overexpressed in HCC [11]. Glypican-3 is so frequently overexpressed in HCC that it can be used as an immunohistochemical marker for the diagnosis of HCC [12]. Very recently, a report has tied these two observations together by suggesting that glypican-3 promotes Wnt signaling, thereby increasing $\beta$-catenin activity in HCC [13]. This report describes an antibody which inhibits the association of glypican-3 with the Wnt receptor frizzled, thereby blocking $\beta$-catenin signaling. Thus, targeted antibodies to glypican-3 may be a way to target $\beta$-catenin-dependent cancers. An alternative approach is the use of drugs referred to as BH3 mimetics, which have also been suggested to target $\beta$-catenin-dependent cancers. $\mathrm{BH} 3$ mimetics are drugs which inhibit Bcl-2 prosurvival family members and/or activate the apoptosis-mediating proteins
Bax and/or Bak. An elegant phenotypic profiling study demonstrated synthetic lethality (fig. 1) between those cancers dependent on $\beta$-catenin and on the Bcl-2 family for survival [14]. Navitoclax, a BH3 mimetic which inhibits $\mathrm{Bcl}-2, \mathrm{Bcl}-\mathrm{XL}$ and $\mathrm{Bcl}-\mathrm{W}$, was shown to be toxic in $\beta$-catenin-dependent cancer cell lines. The role of this for in vivo cancers remains unclear, but it is very intriguing that this could be used to target hepatocellular cancers.

Immune-mediated therapy is highly topical. It has been well recognized that many tumors inhibit $\mathrm{T}$ cell function through inhibitory signals mediated by the B7:CTLA4 pathway or the PD-1:PD-L1 pathway [15]. It has now been recognized that antibodies against PD-1 or the ligand PD-L1 block the inhibitory effect of cancers on $\mathrm{T}$ cells. Recent studies conducted in solid tumors have demonstrated a regression of melanomas and non-small cell lung cancer using inhibitors of this pathway. These studies raised the prospect that immune-directed therapies could also be effective in other solid tumors such as HCC.

\section{Conclusion}

HCC is a very heterogeneous disease due to diverse patient populations, etiology and genetic differences, which can vary between patients, between nodules within a patient and even within a single nodule. Nonetheless, we have made progress in using genetics and stratification for the treatment of patients with HCC. A 5-gene score predicts HCC recurrence after liver resection. We now ap- 
preciate that cancers which overexpress c-MET may perhaps be targeted by c-MET-directed small molecules such as tivantinib. VEGF-A amplification predicted response to sorafenib at least in a retrospective study and may be useful as a prospective biomarker in selecting patients for treatment with sorafenib. The Wnt $\beta$-catenin-driven HCCs may be targetable in the future by antibodies against glypican-3 or using synthetic lethality approaches with $\mathrm{Bcl}-2$ inhibitors. Finally, immune modulation is a promising therapy for solid cancers, although very little data exists on the use of these agents in the treatment of HCC.

\section{Acknowledgements}

The authors would like to thank Ms. Courtney Hoover for excellent secretarial support. This work was supported by NIH grants DK59427 (G.J.G.) and T32 DK007198 (S.R.), and the Mayo Enterprise.

\section{Disclosure Statement}

The authors have nothing to disclose.

\section{References}

1 Yap TA, Gerlinger M, Futreal PA, Pusztai L, Swanton C: Intratumor heterogeneity: seeing the wood for the trees. Sci Transl Med 2012;4: $127 \mathrm{ps} 10$.

2 Nault JC, Zucman-Rossi J: Genetics of hepatocellular carcinoma: the next generation. J Hepatol 2014;60:224-226.

3 Nault JC, Mallet M, Pilati C, Calderaro J, Bioulac-Sage P, Laurent C, Laurent A, Cherqui D, Balabaud C, Zucman-Rossi J: High frequency of telomerase reverse-transcriptase promoter somatic mutations in hepatocellular carcinoma and preneoplastic lesions. Nat Commun 2013;4:2218.

4 Nault JC, De Reynies A, Villanueva A, Calderaro J, Rebouissou S, Couchy G, Decaens T, Franco D, Imbeaud S, Rousseau F, Azoulay D, Saric J, Blanc JF, Balabaud C, Bioulac-Sage P, Laurent A, Laurent-Puig P, Llovet JM, Zucman-Rossi J: A hepatocellular carcinoma 5-gene score associated with survival of patients after liver resection. Gastroenterology 2013;145:176-187.

-5 Santoro A, Rimassa L, Borbath I, Daniele B, Salvagni S, van Laethem JL, van Vlierberghe H, Trojan J, Kolligs FT, Weiss A, Miles S, Gasbarrini A, Lencioni M, Cicalese L, Sherman M, Gridelli C, Buggisch P, Gerken G, Schmid RM, Boni C, Personeni N, Hassoun Z, Abbadessa G, Schwartz B, von Roemeling R, Lamar ME, Chen Y, Porta C: Tivantinib for second-line treatment of advanced hepatocellular carcinoma: a randomised, placebocontrolled phase 2 study. Lancet Oncol 2013; 14:55-63.
6 Gherardi E, Birchmeier W, Birchmeier C, Vande Woude G: Targeting met in cancer: Rationale and progress. Nat Rev Cancer 2012; 12:89-103.

7 Llovet JM, Ricci S, Mazzaferro V, Hilgard P, Gane E, Blanc JF, de Oliveira AC, Santoro A, Raoul JL, Forner A, Schwartz M, Porta C, Zeuzem S, Bolondi L, Greten TF, Galle PR, Seitz JF, Borbath I, Haussinger D, Giannaris T, Shan M, Moscovici M, Voliotis D, Bruix J: Sorafenib in advanced hepatocellular carcinoma. New Eng J Med 2008;359:378-390.

$\checkmark 8$ Horwitz E, Stein I, Andreozzi M, Nemeth J, Shoham A, Pappo O, Schweitzer N, Tornillo L, Kanarek N, Quagliata L, Zreik F, Porat RM, Finkelstein R, Reuter H, Koschny R, Ganten T, Mogler C, Shibolet O, Hess J, Breuhahn K, Grunewald M, Schirmacher P, Vogel A, Terracciano L, Angel P, Ben-Neriah Y, Pikarsky E: Human and mouse VEGFA-amplified hepatocellular carcinomas are highly sensitive to sorafenib treatment. Cancer Discov 2014;4: 730-743.

-9 Boyault S, Rickman DS, de Reynies A, Balabaud C, Rebouissou S, Jeannot E, Herault A, Saric J, Belghiti J, Franco D, Bioulac-Sage P, Laurent-Puig P, Zucman-Rossi J: Transcriptome classification of HCC is related to gene alterations and to new therapeutic targets. Hepatology 2007;45:42-52.

10 Chiang DY, Villanueva A, Hoshida Y, Peix J, Newell P, Minguez B, LeBlanc AC, Donovan DJ, Thung SN, Sole M, Tovar V, Alsinet C, Ramos AH, Barretina J, Roayaie S, Schwartz M, Waxman S, Bruix J, Mazzaferro V, Ligon AH, Najfeld V, Friedman SL, Sellers WR, Meyerson M, Llovet JM: Focal gains of VEGFA and molecular classification of hepatocellular carcinoma. Cancer Res 2008; 68:6779-6788.
1 Llovet JM, Chen Y, Wurmbach E, Roayaie S, Fiel MI, Schwartz M, Thung SN, Khitrov G, Zhang W, Villanueva A, Battiston C, Mazzaferro V, Bruix J, Waxman S, Friedman SL: A molecular signature to discriminate dysplastic nodules from early hepatocellular carcinoma in HCV cirrhosis. Gastroenterology 2006; 131:1758-1767.

12 Tremosini S, Forner A, Boix L, Vilana R, Bianchi L, Reig M, Rimola J, Rodriguez-Lope C, Ayuso C, Sole M, Bruix J: Prospective validation of an immunohistochemical panel (glypican 3, heat shock protein 70 and glutamine synthetase) in liver biopsies for diagnosis of very early hepatocellular carcinoma. Gut 2012;61:1481-1487.

13 Wands JR, Kim M: WNT/ $\beta$-catenin signaling and hepatocellular carcinoma. Hepatology 2014;60:452-454.

14 Basu A, Bodycombe NE, Cheah JH, Price EV, Liu K, Schaefer GI, Ebright RY, Stewart ML, Ito D, Wang S, Bracha AL, Liefeld T, Wawer M, Gilbert JC, Wilson AJ, Stransky N, Kryukov GV, Dancik V, Barretina J, Garraway LA, Hon CS, Munoz B, Bittker JA, Stockwell BR, Khabele D, Stern AM, Clemons PA, Shamji AF, Schreiber SL: An interactive resource to identify cancer genetic and lineage dependencies targeted by small molecules. Cell 2013; 154:1151-1161.

15 Ribas A: Tumor immunotherapy directed at PD-1. New Engl J Med 2012;366:2517-2519. 